\title{
Perancangan Smart Car Menggunakan Speech Recognition Berbasis Arduino Uno
}

\section{Smart Car Design Using Speech Recognition Based on Arduino Uno}

\author{
Hendra Kusumah $^{1}$, Indrianto ${ }^{2}$, Oktorio Ari Pradana ${ }^{3}$ \\ ${ }^{1}$ Dosen STMIK Raharja Jurusan Sistem Komputer, ${ }^{2}$ Dosen STMIK Raharja Jurusan Sistem \\ Komputer, ${ }^{3}$ Mahasiswa STMIK Raharja Jurusan Sistem Komputer \\ hendra.kusumah@raharja.info ${ }^{1)}$, oktorio.ari@ raharja.info' ${ }^{2)}$, indrianto@ raharja.info ${ }^{3)}$
}

\begin{abstract}
Abstrak
Kemajuan ilmu pengetahuan di bidang komputerisasi khususnya mikrokontroler semakin hari semakin meningkat, sehingga mendorong terjadinya arus globalisasi. Perkembangan tersebut tumbuh secara pesat tidak hanya dari bidang komputer saja, selain itu manfaat dari kemajuan teknologi komputer saat ini dapat kita rasakan dalam bidang komputer yang memiliki peranan sangat penting dalam dunia teknologi informasi dan berfungsi sebagai media yang dapat mengolah kreatifitas, dan imajinasi menjadi bentuk yang nyata. Perusahaan PT Indonesia Nippon Seiki yang bergerak di bidang produksi komponen elektrik kendaraan bermotor roda dua dan empat terus berinovasi dalam menciptakan suatu produk Salah satunya adalah menciptakan sebuah alat yang berfungsi dengan menggunakan perintah suara atau ucapan (Spach Recognition), oleh karena itu dalam penelitian ini akan membuat suatu alat speech recognition untuk mengendalikan sebuah kendaraan seperti starter pada kendaraan bermotor yang diaktifkan dengan perintah suara. Pada penelitian ini digunakan metode penelitian analisa, metode perancangan dan metode prototype. Diharapkan dengan adanya penelitian ini dapat mengatasi permasalahan yang dialami pengemudi seperti mempermudah dalam menyalakan mobil, menyalakan lampu utama, dan lampu sein.
\end{abstract}

Kata kunci-Perancangan, Smart Car dan Arduino.

\begin{abstract}
The progress of science in the field of computerization, especially the microcontroller, is increasing every day, thus encouraging the flow of globalization. These developments are growing rapidly not only from the computer field, but also the benefits of advances in computer technology today we can feel in the field of computers that have a very important role in the world of information technology and function as a medium that can process creativity, and imagination into a form that real. PT Indonesia Nippon Seiki company which is engaged in the production of electric components of two-wheeled and four-wheeled motorized vehicles continues to innovate in creating a product. One of them is creating a tool that functions by using voice or speech commands (Speech Recognition), therefore in this study make a speech recognition tool to control a vehicle like a starter on a motorized vehicle that is activated by voice command. In this study used analytical research methods, design methods and prototype methods. It is hoped that this research can overcome the problems experienced by drivers such as making it easier to turn on the car, turn on the main lights, and turn on the lights.
\end{abstract}

Keywords-Perancangan, Smart Car and Arduino. 


\section{PENDAHULUAN}

Perkembangan teknologi komputer saat ini dapat kita rasakan dalam bidang komputer yang memiliki peranan sangat penting dalam dunia teknologi informasi dan berfungsi sebagai media yang dapat mengolah kreatifitas, dan imajinasi menjadi bentuk yang nyata.Sehingga perusahaan PT Indonesia Nippon Seiki yang bergerak di bidang produksi komponen elektrik kendaraan bermotor roda dua dan empat harus berinovasi dalam menciptakan suatu produk Salah satunya adalah menciptakan sebuah alat yang berfungsi dengan menggunakan perintah suara atau ucapan (Spach Recognition), dimana teknologi ini memungkinkan suatu perangkat komputer untuk mengenali dan memahami kata-kata yang diucapkan dengan cara digitalisasi dan mencocokkan sinyal digital tersebut dengan suatu pola tertentu yang tersimpan dalam suatu perangkat. kata-kata yang diucapkan diubah bentuknya menjadi sinyal digital dengan cara mengubah gelombang suara yang masih berupa sinyal analog menjadi sekumpulan angka yang kemudian disesuaikan dengan kode-kode tertentu untuk mengidentifikasi kata-kata tersebut. Hasil dari identifikasi kata yang diucapkan dapat ditampilkan dalam bentuk tulisan atau dapat dibaca oleh perangkat teknologi sebagai sebuah perintah suara untuk melakukan suatu pekerjaan, dan dalam penelitian ini akan membuat suatu alat speech recognition untuk mengendalikan sebuah kendaraan seperti starter pada kendaraan bermotor yang diaktifkan dengan perintah suara.

Smart car merupakan pengintegrasian mobil dengan sistem komputerisasi. Dengan adanya smart car, kenyamanan bagi para pengguna mobil semakin meningkat. Pengontrolan smart car dengan suara merupakan salah satu bentuk pengintegrasian mobil dengan sistem komputerisasi. Pengontrolan smart car dengan menggunakan speech recognition untuk menterjemahkan perintah dan mengontrol.

Penelitian pertama menjelaskan perancang system voice command recognition yang digunakan untuk aplikasi peralatan rumah tangga yang dikendalikan oleh suara pengguna. Perancangan nya menggunakan teknologi Google Voice Recognition system, Arduino Uno, Bluetooth dan teknologi transistor. Dengan Google Voice Recogniton sebagai penerjemah input suara menjadi data berupa string yang kemudian di kirimkan ke arduino untuk di baca melalui membuka pintu pagar dengan sistem pengendalian dan penguncian secara otomatis dengan memanfaatkan kecangihan smartphone melalui media bluetooth untuk pengontrolannya [1].Penelitian berikutnya menjelaskan tentang alat yang memudahkan dalam membuka pintu pagar dengan sistem pengendalian dan penguncian secara otomatis dengan memanfaatkan kecanggihan smartphone melalui media bluetooth untuk pengontrolannya [2]. Penelitian lainnya mengenai alat pengontrol outlet listrik yang digabungkan dengan speech receognition menggunakan raspberry sehingga bisa mengendalikan perangkat elektronik melalui perintah suara [3]. Penelitian selanjutnya membuat alat yang mampu membaca sinyal masukan suara kita dan menyimpannya dalam sebuah modul yaitu Easy VR,Easy VR tersebut akan dihubungkan dengan Mikrokontroler yang akan mengolah logika suara dengan bahasa pemograman yang akan menjadi password untuk membuka Secara logika dapat dibayangkan apabila kita tidak perlu repot membuka pintu rumah saat sedang membawa banyak barang belanjaan, cukup dengan mengatakan "pasword", maka pintu akam terbuka untuk anda secara otomatis [4]. Penelitian lainnya merancang dan membuat suatu peralatan untuk mengendalikan kecepatan putaran motor de dengan perintah suara. Disain peralatan menggunakan sensor easy voice recognition sebagai alat pengkonversi suara menjadi data digital, mikrokontroler Arduino sebagai pengendali utama dan motor dc. Kata-kata yang diucapkan didisain dan diprogram untuk mengatur kecepatan putaran sesuai yang diinginkan. Tegangan masukan untuk mengatur kecepatan motor dc diatur oleh mikrokontroler dengan menggunakan metode PWM [5]. Penelitian lainnya membuat perancangan suatu sistem home automation yang menggunakan perintah suara sebagai masukan. Ketika pengguna mengucapkan perintah melalui mikropon EasyVR, mesin pengenal ucapan EasyVR akan menyesuaikan dengan menu atau database perintah suara Jika mesin pengenal ucapan menemukan kecocokan perintah suara dengan menu perintah suara maka sistem akan memerintahkan peralatan yang cocok untuk dijalankan [6]. 


\section{METODE PENELITIAN}

Secara umum metode penelitian merupakan rencana atau gambaran dari suatu kegiatan yang disusun secara sistematis dan terperinci dengan pada akhirnya akan diikuti dengan realisasi kegiatan itu sendiri. Metode penelitian adalah langkah yang dimiliki dan dilakukan oleh peneliti dalam rangka untuk mengumpulkan informasi atau data serta melakukan investigasi pada data yang telah didapatkan tersebut. Metode penelitian memberikan gambaran rancangan penelitian yang meliputi antara lain: prosedur dan langkah-langkah yang harus ditempuh, waktu penelitian, sumber data, dan dengan langkah apa data-data tersebut diperoleh dan selanjutnya diolah dan dianalisis. Pada penelitian ini metode penelitian yang digunakan meliputi metode analisis permasalahan, metode perancangan sistem untuk membuat rancangan sebuah sistem, dan metode analisis kebutuhan yang diperlukan dalam proses membuat sistem.

Metode pertama, peneliti melakukan analisis permasalahan yang ada dengan cara menentukan dan merumuskan permasalahan yang dihadapi. Secara umum ada 4 (empat) tahapan yang dilakukan dalam mengalisis masalah yaitu: perumusan masalah, membuat spesifik penyebab, menguji penyebab dan memverifikasi penyebab yang sebenarnya. Seringkali menghadapi suatu keputusan dengan berbagai macam alternative pilihan. Untuk menentukan dari sekian banyak alternative tersebut dibutuhkan satu komitmen yang tegas, dan tentunya untuk memenuhi komitmen tersebut juga harus diperlukan beberapa kriteria-kriteria tertentu agar pilihan jatuh pada alternative yang telah matang pertimbangkannya. Pada penelitian ini penulis meneliti di sebuah perusahaan yang bergerak di bidang produksi komponen elektrik kendaraan bermotor roda dua dan empat PT Indonesia Nippon Seiki yang beralamat di Jl. Utama Modern Industri Blok E, Kawasan Industri Modern Cikande Serang - Banten. Penulis mengidentifikasi hasil observasi yang dilakukan di lapangan dan melihat langsung keadaan yang ada di perusahaan tersebut

Metode kedua, metode penelitian yang digunakan setelah analisis permasalahan adalah analisis sistem. Analisa sistem didefinisikan sebagai penguraian dari suatu system informasi yang utuh ke dalam bagian-bagian komponennya dengan maksud untuk mengidentifikasikan dan mengevaluasi permasalahan-permasalahan, kesempatan-kesempatan, hambatan-hambatan yang terjadi dan kebutuhan-kebutuhan yang diharapkan sehingga dapat diusulkan perbaikanperbaikannya. Analisis sistem adalah suatu kegiatan untuk mengidentifikasi suatu permasalahan yang terjadi agar kebutuhan dapat dipenuhi dalam sistem baru. Pada metode ini penulis menganalisa sistem-sistem yang sudah ada dengan beberapa poin pertimbangan seperti bagaimana cara kerja sistem, apa saja kompenen yang membangun sistem tersebut dan juga kekurangan dari sistem tersebut.

Metode ketiga, Perancangan sistem merupakan tahap selanjutnya setelah analisa sistem, mendapatkan gambaran dengan jelas tentang apa yang dikerjakan pada analisa sistem, maka dilanjutkan dengan memikirkan bagaimana membentuk sistem tersebut. Perancangan sistem adalah suatu tahapan perencanaan untuk membentuk suatu sistem agar dapat berfungsi. Untuk metode perancangan, penulis menggunakan Flowchart. Alasan penulis memilih metode perancangan flowchart ini adalah dalam metode perancangan program sebelumnya penulis menggunakan flowchart, sehingga dalam metode perancangan ini penulis menggunakan metode yang sama agar dapat saling berhubungan dan tidak ada yang berubah, hanya saja ada perubahan atas sistem yang akan diusulkan, namun tidak akan merubah konsep kerja pada sistem yang sedang berjalan. Untuk perancangan alat, penulis menggunakan Sistem Flowchart, dan untuk perancangan program, penulis menggunakan Flowchart Program.

Metode keempat, yaitu metode analisis kebutuhan, Dalam hal ini analisis kebutuhan merupakan satu alat yang tepat sebagai pelengkap bagi evaluator program ketika mempertimbangkan kejelasan masalah, serta memberikan rekomendasi kepada penentu kebijakan. Dalam perancangan perangkat keras ini dibutuhkan beberapa komponen elektronika serta device penunjang agar sistem dapat berjalan dengan baik sesuai dengan fungsinya. Dan di dalam perancangan alat ini didukung oleh beberapa software yang digunakan baik untuk arduino uno maupun untuk pembuatan sistem aplikasi pada Smart car ini. 


\section{HASIL DAN PEMBAHASAN}

\subsection{Analisis permasalahan}

Melakukan analisis permasalahan yang ada dengan cara menentukan dan merumuskan permasalahan yang dihadapi. Berdasarkan hasil yang telah dilakukan terhadap sistem yang berjalan dapat dilihat beberapa permasalahan yang dihadapi dalam berkendara, pada saat berkendara pengemudi membutuhkan konsentrasi dalam berkendara. Beberapa aktivitas pengemudi seperti pada saat menjangkau panel instrumen dapat mengurangi konsentrasi pengemudi dalam berkendara sehingga rentan terhadap kondisi kecelakaan.

3.2 Metode Analisa Sistem

Analisis sistem adalah suatu kegiatan untuk mengidentifikasi suatu permasalahan yang terjadi agar kebutuhan dapat dipenuhi dalam sistem baru Berdasarkan hasil analisa pada PT Indonesia Nippon Seiki yang beralamat di Jl. Utama Modern Industri Blok E, Kawasan Industri Modern Cikande Serang - Banten. Penulis mengidentifikasi hasil observasi yang sudah dilakukan di lapangan dan melihat langsung keadaan yang ada di perusahaan tersebut, maka di dapatkan bahwa smart car ini memiliki kelebihan dan kekurangan.

\section{Kelebihan:}

a. Mengendalikan panel instumen kendaraan hanya dengan ucapan.

b. Mengeluarkan feedback berupa suara ucapan jika mesin berhasil di hidupkan, seatbelt belum terpasang ketika kendaraan berjalan dan jika kecepatan melebihi batas dapat diatur.

c. Pengenalan ucapan dapat diatur untuk hanya dapat mengenali logat yang telah ditentukan (sistem dapat dilatih dengan melakukan perekaman terlebih dahulu untuk beberapa perintah yang nantinya akan dikenali untuk dapat mengendalikan panel instrumen dengan ucapan), maka sistem ini hanya dapat mengenali ucapan dengan logat yang sesuai dengan apa yang telah di ajarkan kepada sistem, dengan demikian tidak sembarang orang yang dapat mengendalikan panel instrumen dengan ucapan.

d. Meningkatkan keamanan kendaraan dalam berkendara.

Kekurangan :

a. Tidak semua fitur yang dikendalikan dari panel instumen bisa dikendalikan juga melalui ucapan.

b. Hanya dapat mengenali maksimal 7 (tujuh) ucapan perintah suara.

c. Untuk melatih sistem maka alat harus diprogram ulang dengan coding untuk merecord perintah suara yang baru.

d. Kurang optimal jika digunakan dalam kabin yang penuh dengan voice suara.

\subsection{Metode Perancangan Sistem}

Pada tahap pembuatan sebuah kontrol diperlukan sebuah gambar yang nantinya akan menjelaskan suatu alur atau langkah langkah dari sebuah kerja sistem yang dibuat, sehingga dapat memberikan penjelasan dalam bentuk gambar. Penjelasan yang berupa gambar proses kerja sebuah sistem yang merupakan gambar dari sistem yang dibuat. Tujuan dari pembuatan flowchart adalah untuk mempermudah pembaca dan pembuat sistem itu sendiri untuk memahami langkah-langkah serta cara kerja sebuah sistem yang dibuat. Dari penelitian yang dilakukan menghasilkan flowchart dibawah ini berikut ini Untuk perancangan alat, penulis menggunakan Sistem Flowchart untuk perancangan program : 


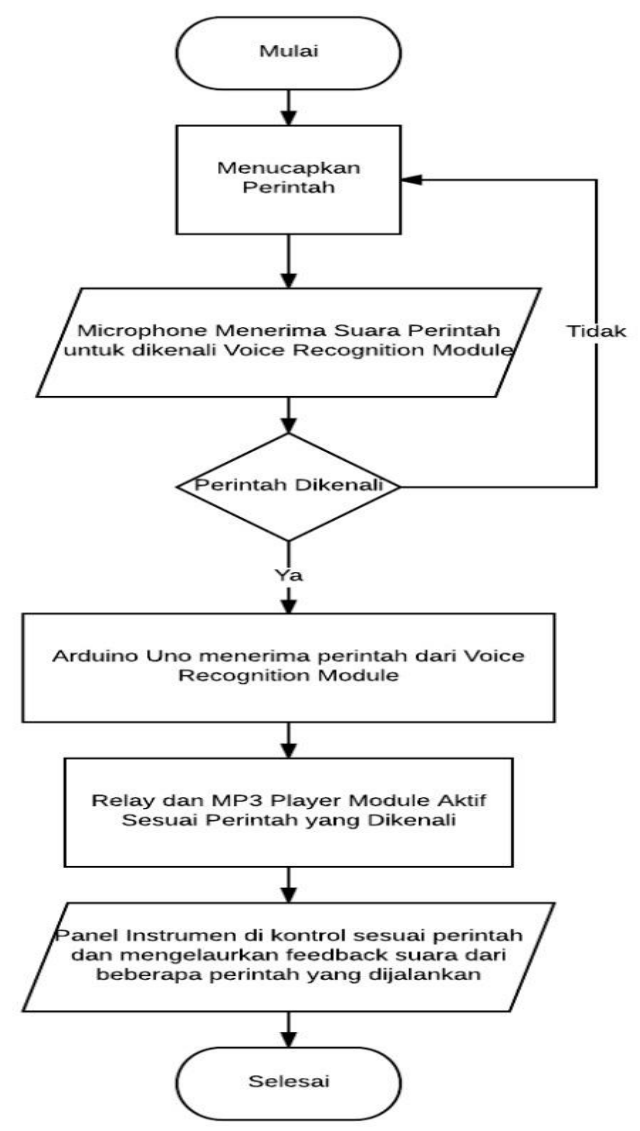

Gambar 1. flowchart sistem yang Berjalan

Alat ini bekerja dengan cara menerima input suara dari user, yang di terima oleh modul speech recognition. Lalu modul voice recognition menterjemahkan perintah suara yang di kenali untuk kemudian di proses oleh arduino uno untuk melakukan beberapa proses seprti menyalakan mesin ,lampu utama, lampu sen. Berikut ini penulis kelompokan mejadi 3 bagian yang terdiri dari cara sistem input, sistem proses, dan sistem kerja output sebagai berikut :

- Input

Pada sistem input komponen yang di gunakan adalah microfon yang terhubung dengan voice recognition modul, perintah suara yang diucapkan oleh user akan di terima oleh voioce recogniot modul melalui microfon. Voice recognition modul akan mencocokan perintah suara yang di terima dengan perintah sauara yang sudah tersimpan, apabila perintah sesuai maka voice recognition modul akan menginstruksikan kepada arduino untuk menjalankan fungsi pengontrolan sesuai perintah yang di terima. Sistem input selanjutnya yaitu smart phone yang terhubung dengan jaringan internet yang berfungsi sebagai pengendali panel-panel instrument melalui aplikasi blynk.

- Proses

Pada sistem proses terdapat komponen arduino uno yang di dalamnya terdapat cip atmega 328. Mikrokontroler bertindak sebagai komponen yang akan memproses data intruksi yang di terima dari voice recognition modul untuk menjalankan komponen otput. Pada aerduino uno terhubung dengan komponen arduino ethernet yang berfungsi untuk menghubungkan arduino dengan jaringan internet.

- Output

Pada sistem ouotput terdapat komponen relay yang berfungsi untuk mengendalikan beberapa panel instrument. relay ini terhubung dengan sistem klistrikan pada setiap komponen panel instrument, seperti lampu utama, lampu seind dan menyalakan mesin mobil (starter). Relay ini akan aktif ketika menerima data dari arduino uno. Selanjutnya 
terdapat komponen mp3 player yang terhung dengan speaker yang akan mengeluarkan feedback sesuai data output dari arduino uno.

\subsection{Metode Analisis Kebutuhan}

Analisis kebutuhan yang dilakukan yaitu mengidentifikasikan seluruh kebutuhan yang diperlukan untuk membangun sebuah sistem baru. Perancangan sistem secara keseluruhan memerlukan beberapa alat dan bahan yang digunakan untuk memenuhi kebutuhan dalam pembuatan sistem meliputi perangkat keras (hardware) dan perangkat lunak (software). Alat yang digunakan meliputi Tang, Obeng, Solder, Kabel USB Type A-B, PC \& Laptop, dan Hand Phone (smartphone).

Software Arduino IDE, dan Aplikasi Blynk. Sedangkan bahan-bahan yang digunakan : Arduino Uno, Electhouse Voice Recognition Module, DFPlayer MP3 Player Module, Modul Relay, DC-DC Buck Converter, Jack 3.5mm Female, MicroSD, Timah,Kabel, LED, Speaker, Resistor, PCB, Arduino Ethernet, Wifi access point.

Perangkat Keras (Hardware) Dalam perancangan perangkat keras ini dibutuhkan beberapa komponen elektronika serta device penunjang agar sistem dapat berjalan dengan baik sesuai dengan fungsinya. Adapun beberapa penjelasan mengenai rangkaian-rangkaian yang meliputi alat yang dibuat. Diantarnya sebagai berikut :

a. Elechouse Voice Recognition Module

Elechouse voice recognition module adalah modul untuk mengenali perintah suara seperti perintah dalam bentuk ucapan ataupun suara. Modul ini mendukung hingga 80 perintah suara dengan maksimal 7 perintah suara yang dapat bekerja secara bersamaan, dengan setiap perintah suara berdurasi 1500 milisecond atau sekitar satu atau dua ucapan kata. Sebelum digunakan modul ini harus di latih agar dapat mengenali setiap perintah suara. Voice recognition module ini memiliki dua cara untuk mengendalikan nya, yaitu dengan serial port (full function), dan general input pin (part of function). General ourtput pin di modul ini dapat menghasilkan beberapa jenis gelombang saat perintah suara dikenali oleh modul.

b. DFPlayer Mini

DFPlayer Mini adalah modul MP3 player yang ringkas dengan output yang telah di sederhanakan untuk langsung ke speaker, modul ini dapat digunakan sebagai modul yang independen dengan baterai, tombol, speaker yang terpasang atau digunakan sebagai kombinasi dengan Arduino UNO atau perangkat lain nya dengan kemampuan Rx / Tx. Modul ini memiliki mode kontrol yang bervariasi, yaitu mode kontrol I/O, mode serial, dan mode kontrol AD Button. Volume output dari modul ini mempunyai 30 level yang dapat di sesuaikan serta 6 level equalizer yang dapat di sesuaikan juga.

c. Relay

Relay secara sederhana adalah sebuah saklar yang terdiri dari bagian elektrikal yang merupakan kumparan elektromagnet dan mekanikal yaitu terdiri juga dari kontak mekanis. Jadi tanpa adanya arus listrik, relay tidak bisa beroperasi atau kontaknya tidak bisa berpindah dari NC ke NO dan sebaliknya. Fungsi sebuah relay utamanya adalah sebagai sebuah saklarelektronik yang diperlukan ketika diperlukan untk mengontrol arus dan tegangan yang tinggi tetapi dengan kontrol dari hanya arus kecil saja, misalnya saja mengontrol arus $220 \mathrm{VAC}$ tetapi hanya dengan tegangan $6 \mathrm{VDC}$ saja.

d. DC-DC buck-converter

Konverter adalah perubahan tegangan DC ke tegangan DC lainnya dalam level atau polaritas yang berbeda. Ketika tegangan DC yang tersedia tidak sesuai dengan tegangan yang dibutuhkan oleh suatu perangkat atau rangkaian elektronik, maka digunakanlah konverter. Karena itu konverter merupakan bentuk power-supply juga.

e. Led

Light emitting diode atau sering disingkat dengan LED adalah komponen elektronika yang dapat memancarkan cahaya monokromatik ketika diberikan tegangan maju. LED merupakan keluarga dioda yang terbuat dari bahan semi konduktor. Warna-warna cahaya 
yang dipancarkan oleh LED tergantung pada jenis bahan semikonduktor yang dipergunakannya. LED juga dapat memancarkan sinar inframerah yang tidak tampak oleh mata seperti yang sering kita jumpai pada remote control TV ataupun remote control perangkat elektronik lainnya.

f. Speaker

Komponen Elektronika yang bernama Loudspeaker dalam bahasa Indonesia disebut dengan pengeras suara. Loudspeaker atau lebih sering disingkat dengan speaker adalah transduser yang dapat mengubah sinyal listrik menjadi frekuensi audio (sinyal suara) yang dapat didengar oleh telinga manusia dengan cara mengetarkan komponen membran pada speaker tersebut sehingga terjadilah gelombang suara.

g. Jack $3.5 \mathrm{~mm}$

Konektor Audio 3.5mm Jack adalah sebuah konektor audio yang terdapat pada kebanyakan smartphone yang diproduksi sekarang ini. Konektor $3.5 \mathrm{~mm}$ Jack dijadikan standar internasional karena kemampuan dan fiturnya yang lebih memadai ketimbang konektor Audio $2.5 \mathrm{~mm}$ Jack. Kata $3.5 \mathrm{~mm}$ Jack sendiri diambil dari ukuran diameter konektor tersebut. Konektor $3.5 \mathrm{~mm}$ Jack ini juga memiliki tipenya sendiri-sendiri.

h. Arduino Ethernet

Arduino Ethernet Shield menghubungkan papan mikrokontroler Arduino ke internet. Arduino Ethernet Shield berbasis Wiznet W5100 ethernet chip. Agar dapat terhubung dengan intemet, kabel RJ45 untuk menghubungkan Arduino Ethernet Shield dengan koneksi internet. Uno, Duemilanove, dan Mega merupakan jenis papan pengendali Arduino yang cocok dengan Arduino Ethernet Shield.

i. Micro SD

MicroSD adalah kartu memori non-volatile yang dikembangkan oleh SD Card Association yang digunakan dalam perangkat portable. Keluarga microSD yang terbagi menjadi SDSC yang kapasitas maksimum resminya sekitar 2GB, meskipun beberapa ada yang sampai 4GB. SDHC (Hight Capacit) memiliki kapasitas dari 4GB sampai 32GB. Dan SDXC (Extended Capacity) kapasitasnya diatas 32GB hingga maksimum 2TB. Keberagaman kapasitas seringkali membuat kebingungan karena masing-masing protokol komunikasi sedikit berbeda.

j. Arduino Uno

Arduino Uno adalah sebuah board mikrokontroller yang di dasarkan pada ATMega328 (datasheet). Arduino Uno mempunya 14 pin digital input/uotput (6 diantarnya dapat digunakan sebagai output PWM), 6 input analog, sebuah asilator Kristal $16 \mathrm{MHz}$, sebuah koneksi USB, sebuah power jac, sebuah ICSP header, dan sebuah tombol reset. Arduino Uno yang memuat semua yang dibutuhkan untuk menunjang mikrokontroller, mudah menghubungkan ke sebuah komputer dengan sebuah kabel USB atau mensuplainya dengan sebuah adaptor AC ke DC atau menggunakan baterai untuk memulainya.

k. TP-Link access point

Router ini mempunyai fungsi diantaranya $3 \mathrm{G}$ mode, WISP mode dan AP mode. $3 \mathrm{G}$ mode berfungsi untuk membuat wifi dari $3 \mathrm{G}$ wireless modem, baik itu CDMA ataupun GSM. WISP mode berfungsi sebagai penerima wireless berbasis WISP. sedangkan AP mode berfungsi sebagai cliemt, repeater, bridge dan lain-lain. TP-link yang di gunakan bertipe MR3020 yang terhubung dengan arduino ethernet menggunakan kabel RJ45.

\subsection{Rangkaian Sistem Keseluruhan}

Setelah melakukan perancangan perangkat keras dari seluruh komponen dan bahan yang digunakan, maka rangkaian sistem keseluruhan akan terlihat seperti berikut : 


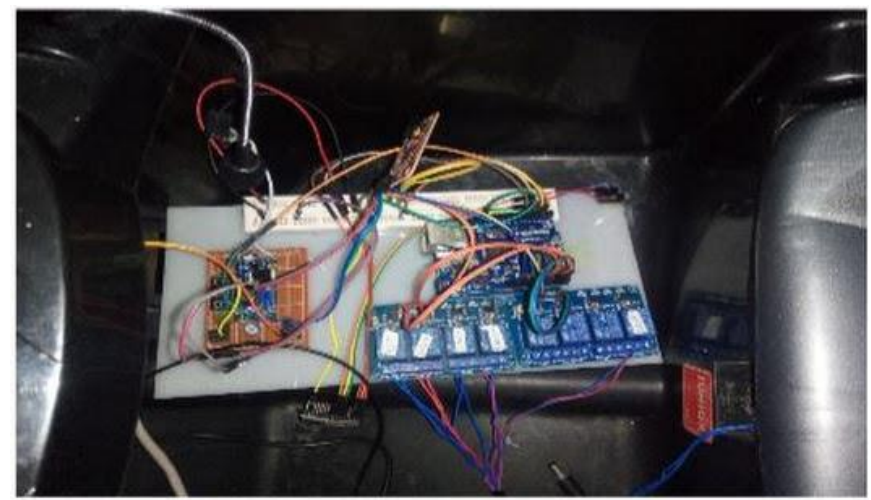

1. Instalasi Driver

Gambar 2. Keseluruhan alat

Untuk memprogram mikrokontroller ATMega328 atau Arduino Uno dibutuhkan software Arduino IDE (Integrated Developmen Environment) karena software ini mudah dalam membuat fuingsi-fungsi logika dasar mikrokontroller dan sangat mudah dimengerti karena mengguanakan bahasa C, selain software Arduino IDE untuk memasukan program ke dalam sebuah mikrokontroller ATMega328, dibutuhkan Driver USB,IDE Arduino 1.0.5 dan Arduino Uno Board agar program yang dibuat dapat berjalan didalam mikrokontroller.

Pada pembahasan ini adakan dijelaskan langkah-lanhgkah instalasi Driver untuk Arduino Uno dengan windows 10, Vista atau XP :

1. Hubungkan Board dan tunggu Windows untuk memulai proses instalasi driver. Setelah beberapa saat, biasanya prosesn ini akan gagal.

2. Klik pada tombol Start buka Control Panel.

3. Setelah memilih Control Panel, langkah selanjutnya masuk ke menu System and Security, kemudian klik pasa System. Setelah tampilan System muncul buka Device Manager.

4. Lihat pada bagian Port (COM\&LTP). Anda akan melihat port terbuka dengan nama "Arduino Uno (COMxx)".

5. Klik kanan pada port "Arduino Uno (COMxx)"dan pilih opsi "Update Driver Software".

6. Kemudian pilih opsi "Browser My Computer For Driver Software".

7. Terakhir, masuk dan pilih file driver Uno, dengan nama "ArduinoUNo.inf".

2. Membuat Project

1. Buka Software Arduino 1.8.0 yang dapat dilihat pada gambar dibawah ini :

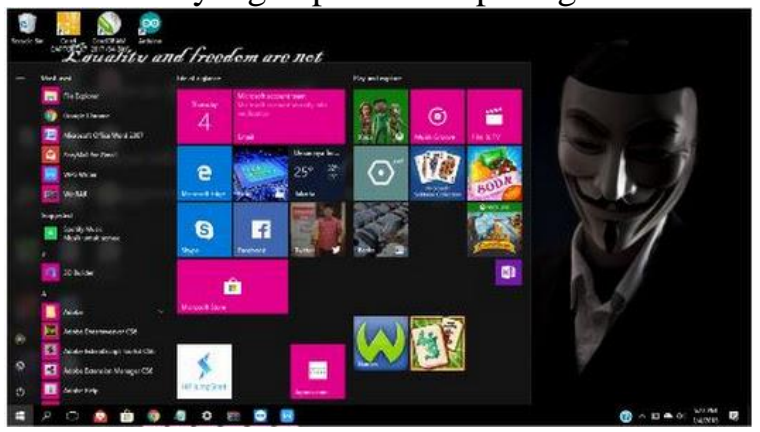

Gambar 3. Membuka Software Arduino

2. Kemudian akan muncul sebuah layer untuk menulis program yang dapat dilihat dari gambar berikut : 
3. Mengecek Listing Program

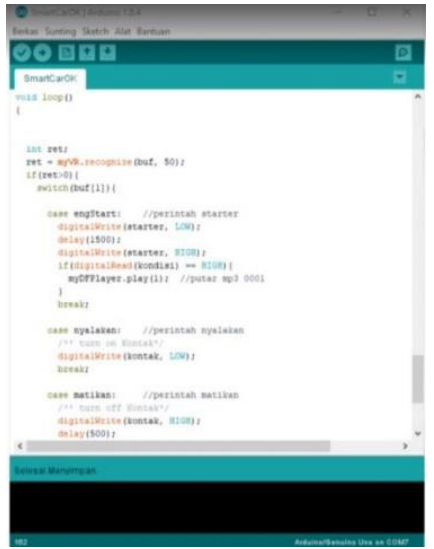

Gambar 4. Membuat Coding Program

Setelah listing program ditulis maka langkah selanjutnya ialah proses kompilasi untuk mengecek apakan listing program yang ditulis terjadi kesalahan atau tidak, pilih menu "Verify" yang dapat dilihat pada gambar di bawah ini :

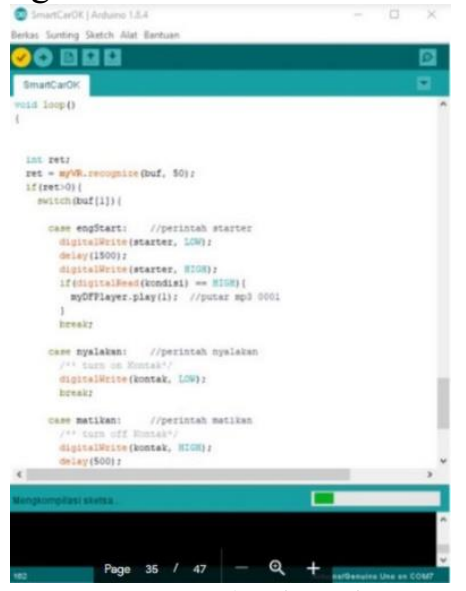

4. Menentukan Koneksi Port

Gambar 5. Mengecek Listening Program

Setelah mengecek listing program tidak ada kesalahan maka langkah selanjutnya ialah memilih port. Pada pemrograman ini koneksi port perlu di perhatikan, karena pada pengalamatan port inilah mikrokontroller dapat berkomunikasi dengan PC atau laptop melalui komunikasi serial. Langkah nya memilih port ialah dengan cara meng-klik menu Alat, kemudian pilih serial port atau dapat dilihat pada gambar di bawah ini :

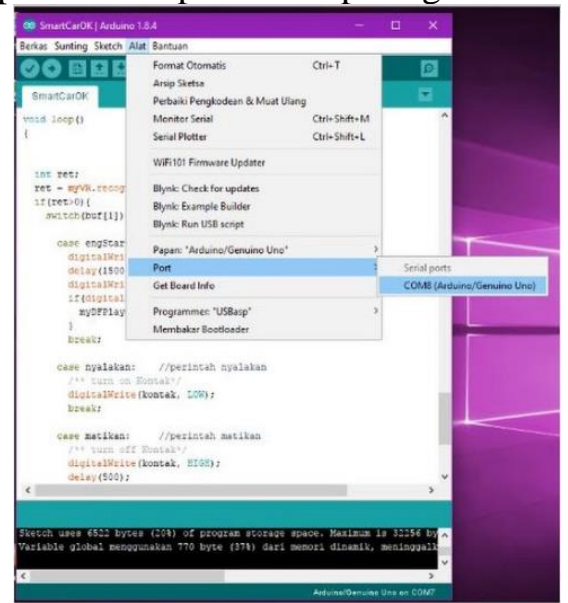

Gambar 6. Menentukan Port USB 
5. Save As dan Pemilihan board

Setelah selesai melakukan pemulisan serta pengecekan listing program maka langkah selanjutnya ialah menyimpan file tersebut dengan cara Klik file - Save as, setelah itu program perlu di sesuaikan dengan board yang digunankan, yaitu dengan cara memilih menu Alat - Board (pilih salah satu sesuai dengan Arduino yang digunakan), atau dapat dilihat pada gambar di bawah ini :

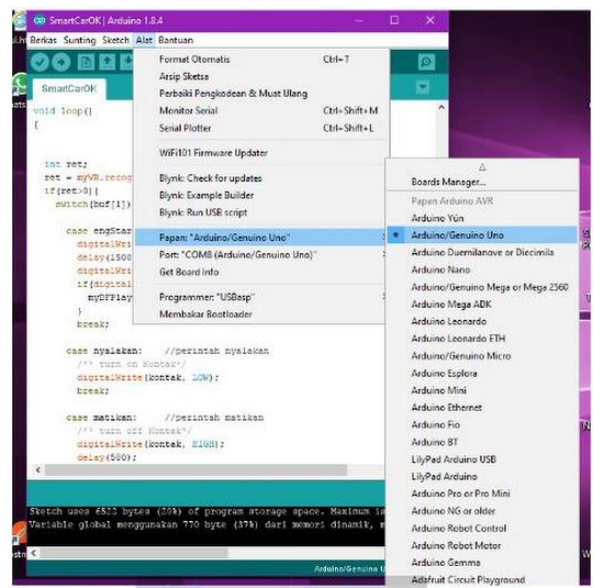

Gambar 7. Menyimpan Program

6. Upload Program

Tahapan terakhir ialah memasukkan program ke dalam mikrokontroler, klik "Upload" dan tunggu sampai selesai atau lebih jelas lihat gambar di bawah ini :

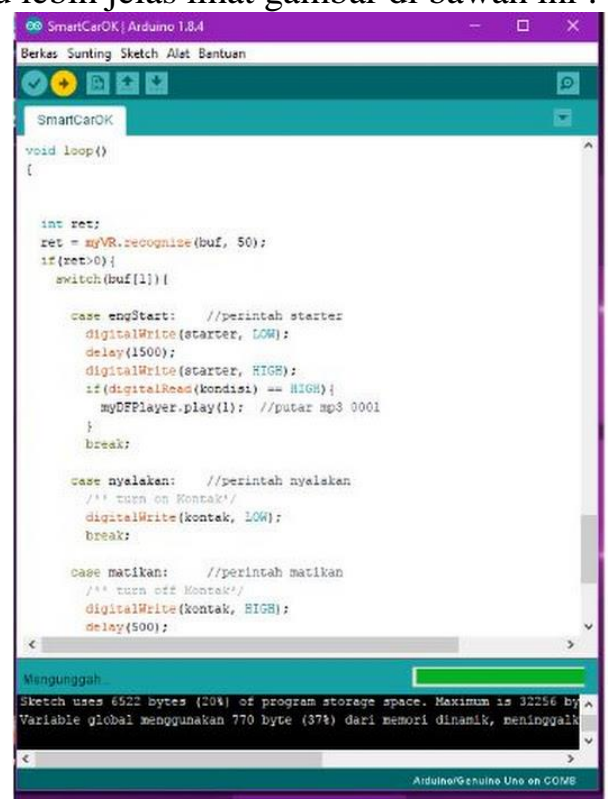

7. Instalasi Blynk

Gambar 8. Mengaupload program

Blynk app merupakan aplikasi pada smartphone yang berfungsi sebagai dasbor untuk mengendalikan perangkat yang terhubung dengan jaringan internet, perangkat tersebut berupa arduino uno yang telah di integrasikan dengan arduino ethernet shield sebagai antar muka arduino uno dengan jaringan internet.

Blynk app dapat di unduh di Google Play Store atau Apps Store, setelah Blynk app terinstall selanjutnya blynk app harus di konfigurasi, konfigurasi meliputi akun email, token, dan dasbor. 


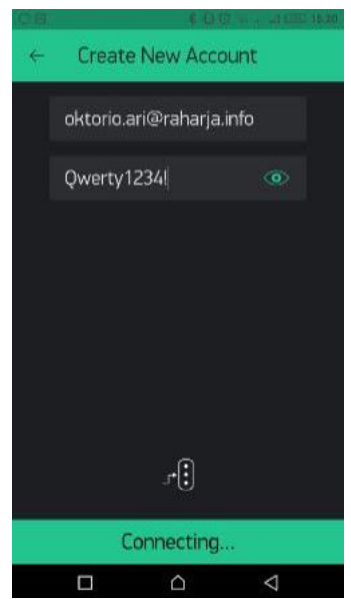

Gambar 9. Konfigurasi Akun Email

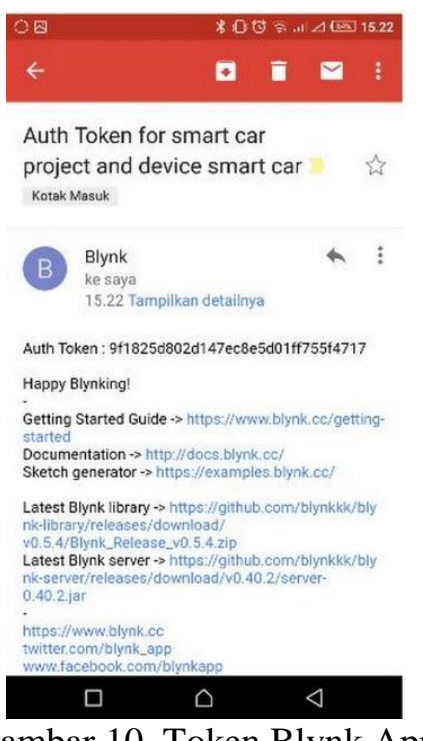

Token yang didapatkan dari email yang didaftartkan pada blynk app harus dimasukan ke listing program yang akan di upload ke arduino uno agar alat yang digunakan dapat terhubung dengan smartphone. Konfigurasi dasbor dilakukan dengan menambahkan widget button pada blynk app, widget button di tambahkan sesuai dengan fungsi pada smart car.

\section{KESIMPULAN}

Berikut ini kesimpulan perihal rumusan masalah mengenai Prototype Rancang Bangun Keamanan Loker Penyimpanan Barang Menggunkan Voice Berbasis Arduino Uno Pada adalah sebagai berikut:

a. Alat ini dapat di perintah dengan metode Speech Recognition sesuai dengan apa yang diperintahkan melalui aplikasi pada Smartphone.

b. Speech recognition dapat membantu karyawan kantor dalam menyimpan barang berkas ke dalam loker dengan menggunakan kunci yang dilakukan secara voice realtime pada lokasi berjauhan.

c. Dengan adanya prototype ini di harapkan dapat di implementasikan pintu dengan dukungan voice recognition yang direkomendasikan ke pihak manufaktur.

d. Dapat meningkatkan keamanan. 


\section{SARAN}

Berikut ini saran perihal rumusan masalah mengenai Prototype Smart Car Menggunakan Spach Recognition Berbasis Arduino Pada PT. Indonesia Nippon Seiki yaitu semua produksi kendaraan dapat menggunakan sistem ini sehingga mempermudah pengguna dalam mengoperasikan kendaraan dan diharapkan hasil rancangan ini bisa di kembangkan lebih lanjut agar bisa memudahkan dalam pengerjaaan sesuatu dengan praktis dan efisien.

\section{UCAPAN TERIMA KASIH}

Ucapan terima kasih penulis kepada Perguruan Tinggi Raharja yang telah memberi dukungan, fasilitas, serta finansial sehingga penulis dapat menyelesaikan penelitian ini dengan baik.

\section{DAFTAR PUSAKA}

[1] Dani, akhmad wahyu, Andi Adriansyah, Dodi Hermawan. 2016. Perancangan Aplikasi Voice Command Recognition Berbasis Android Dan Arduino Uno. Jurnal Teknologi Elektro. Universitas Mercu Buana. Vol.7 No.1 Januari 2016.

[2] Alpurqon, Agung. 2014. Sistem Pengendali Pagar Secara Otomatis Menggunakan Aplikasi Voice Command Pada Smartphone Android OS. Tugas Akhir. Perguruan Tinggi Raharja.

[3] Azizah, Nur. 2017. Prototype Pengontrolan Outlet Listrik Dengan Suara Menggunakan Rasbbery Pi Pada PT. Informedian Solusi Humanika. Skripsi. Perguruan Tinggi Raharja.

[4] N. Seppiawan, Ashar, Nurussa'ada dan Ponco Siwindarto. 2014. Sistem Keamanan Pintu Pagar Otomatis Menggunakan Voice Recognition. Jurnal Mahasiswa TEUB Vol. 2 No. 6. 2014.

[5] Birdayansyah, Radi, Noer Sudjarwanto dan Osea Zebua. 2015. Pengendalian Kecepatan Motor DC Menggunakan Perintah Suara Berbasis Mikrokontroler Arduino. Jurnal Rekayasa dan Teknologi Elektro Volume 9, No. 2, Mei 2015.

[6] Tambak, Terhulin Purba dan T. Ahri Bahriun. 2015. Perancangan Sistem Home Automation Berbasis Arduino Uno. Singuda Ensikom Vol.10 No.28 Maret 2015. 